Abstracta Iranica Abstracta Iranica

Revue bibliographique pour le domaine irano-aryen

Volume 37-38-39 | 2018

Comptes rendus des publications de 2014-2016

\title{
Vito Messina (ed.). Hung-e Azhdar. Research of the Iranian-Italian Joint expedition on Khuzestan (2008-2011)
}

\section{Rémy Boucharlat}

\section{(2) OpenEdition \\ Journals}

Édition électronique

URL : http://journals.openedition.org/abstractairanica/47074

DOI : 10.4000/abstractairanica.47074

ISBN : 1961-960X

ISSN : 1961-960X

Éditeur :

CNRS (UMR 7528 Mondes iraniens et indiens), Éditions de l'IFRI

Référence électronique

Rémy Boucharlat, «Vito Messina (ed.). Hung-e Azhdar. Research of the Iranian-Italian Joint expedition on Khuzestan (2008-2017) », Abstracta Iranica [En ligne], Volume 37-38-39 | 2018, document 71, mis en ligne le 30 décembre 2018, consulté le 02 octobre 2020. URL : http://journals.openedition.org/ abstractairanica/47074 ; DOI : https://doi.org/10.4000/abstractairanica.47074

Ce document a été généré automatiquement le 2 octobre 2020.

Tous droits réservés 


\title{
Vito Messina (ed.). Hung-e Azhdar. Research of the Iranian-Italian Joint expedition on Khuzestan (2008-2011)
}

\author{
Rémy Boucharlat
}

\section{RÉFÉRENCE}

Vito Messina (ed.). Hung-e Azhdar. Research of the Iranian-Italian Joint expedition on Khuzestan (2008-2011). Parthica, 17, 2015, 234p., 6 p. résumé persan., ill., 16 Pl. couleur

1 Ce numéro entier de la revue Parthica est consacré aux résultats de la mission conjointe Iran-Italie à Hung-e Azhdar, le site d'un bas-relief parthe rupestre à $17 \mathrm{~km}$ au nord de la ville d'Izeh. Soulignons que ce programme de quatre ans a été mené en 2008-2011 par V. Messina et J. Mehr Kian et publié dès 2016. L'objet de la recherche était un relief sculpté sur un énorme rocher isolé et son environnement immédiat qui a été l'objet de recherches de terrain, dont des sondages archéologiques au pied du relief. À noter que ces images sont sculptées, non pas face à la vallée, qui porte par ailleurs un bas-relief élamite du IIe mill. très érodé, mais sur la face qui regarde la montagne, donc très peu visible. Il est une illustration de plus que ces images ne sont pas à interpréter comme des documents de propagande.

Plus que bien d'autres reliefs d'époque parthe ou élyméenne, Hung-e Azhdar pose un problème de chronologie car il présente deux parties de styles très différents. À gauche un cavalier sur son cheval, vu de profil, dont le style et les ddétails iconographiques étaient datés de Mithridate I (après 140. av.n.è.) par la plupart de spécialistes, à droite une série de quatre personnages debout représentés strictement selon la frontalité parthe. Cette partie a été le plus souvent datée de la fin de l'époque parthe (entre la fin du IIe et le début IIIe s. d. n.è.), soit environ trois siècles de différence entre les deux parties. Quelques auteurs suggéraient, sans grande conviction, que le relief pourrait 
être l'œuvre de deux ateliers distincts mais travaillant à la même époque. Les travaux de la mission ont apporté des résultats novateurs et solides.

VM donne un historique des recherches (pp. 15-36) qui présente les différentes interprétations et datations. Dans le chapitre suivant, à partir des relevés scanner et photogrammétriques, il analyse minutieusement les images retravaillées représentées en modèle 3D. Tous les détails des surfaces travaillées sont scrutés centimètre par centimètre, à la recherche de traces de travail ou de reprise sur les personnages et sur les objets ajoutés dans le champ. La représentation de près de la tête du cavalier et d'un personnage de face, comparée aux monnaies de ces époques, conduit VM à y voir dans le premier, non pas Mithridate $I$, mais un Kamnaskirès d'Elymaiïde du Ier s. av.n.è. et dans le second Kamnaskirès-Orodes, d'Elymaïde également, au début du IIe s. d. n.è.

Les sondages au pied du relief ont révélé deux phases archéologiques mais la stratigraphie est très perturbée par des fouilles illégales antérieures et par le passage des hommes et des troupeaux. Des tessons de poteries de l'époque élamite à l'époque parthe se trouvent mélangés dans une même couche. Parmi les modestes structures mises au jour (voir la reconstitution proposée fig. 40), on observe une banquette en pierres brutes installées sur une terrasse à environ $5 \mathrm{~m}$ en face du relief, et une plateforme en pierres et cailloux au pied du relief de même longueur que celui-ci, reconstruite trois fois. Le matériel, non en place, étudé par d'autres membres de l'équipe, offre une importante collection de pointes de flèches en fer dont un grand nombre a été trouvé devant la plateforme. Ces petits objets ainsi qu'une série de clochettes en bronze ont, selon les fouilleurs, une fonction votive, mais de là à imaginer que ce sont des guerriers qui les ont déposés me semble hypothétique. Posséder un arc n'est pas l'apanage du guerrier. La plateforme aurait porté un autel s'il recevait des offrandes ou ex-voto, tandis que la longue banquette face au relief aurait pu être le soubassement d'une construction, suggèrent les auteurs.

5 La publication de cette opération est exemplaire de précision sur les travaux sur le basrelief, les pauvres restes architecturaux et le modeste matériel recueilli. L'illustration très abondante est dans la tradition de la grande qualité de Parthica.

\section{AUTEURS}

\section{RÉMY BOUCHARLAT}

UMR 5133 CNRS-Université de Lyon 